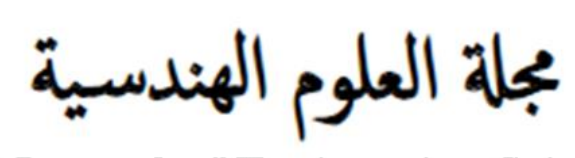

FES Journal of Engineering Sciences

http://journal.oiu.edu.sd/ojs/index.php/fjes/index

\title{
Investigations on Coil Geometry in WPT Systems for Charging EVs Applications
}

\author{
Elnail Kamal Eldin Idris Ahmed ${ }^{1, *}$ \\ 1 Sudan Technological University, Omdurman, Sudan \\ * Corresponding author: Elnail Kamal Eldin Idris Ahmed (e-mail: elneelka@hotmail.com ). \\ Article history: Received 21 Dec. 2021, Received in revised form 03 Jan. 2022, Accepted 14 Jan. 2022 \\ Digital Object Identifier (doi): https://doi.org/10.52981/fjes.v11i1.1770
}

\begin{abstract}
This paper investigates different coil geometries for designing wireless power transfer (WPT) system for electric vehicle (EV) applications. The system model depends on the lumped parameters model using series-series (SS) compensation topology is briefly discussed. The investigations adopted comparing the coupling coefficient using Finite Element Method (FEM) software when the two coils are laterally and vertically misaligned. Moreov comprising the electromagnetic flux density distributions. One turn coreless circular planar and square planar coils are simulated and the results are depicted and compared for the same wire length. The results show that the circular coil gained a higher coupling coefficient and generated more electromagnetic flux density than the square coil.
\end{abstract}

Keywords: Wireless Power Transfer, Coils Geometry, Circular Coils, Square Coils.

\section{INTRODUCTION}

Nowadays, developing electric vehicle (EV) systems have drawn much attention as one of new high-performance clean technology in the transportation sector [1]. According to the United States Environmental Protection Agency (EPA), transportation in the US contributed by $29 \%$ of greenhouse gases in 2019 [2]. Moreover, since the transportation sector consumes about $70 \%$ of the petroleum products and other natural resources [3], [4]. Therefore the reasons of economic considerations, energy security and environmental issues there is an increasing demand for replacing the internal combustion engine (ICE) vehicles with EVs [5], [6]. EV outperformed the traditional ICE vehicle in term of less noise, less routine maintenance, high performance, and zero tailpipe emissions [7].

However, despite many potential benefits, to date, the mass acceptance of EVs has been delayed by two key factors: 1) the supposed limitations (short mileage and long time to recharge the EV battery) and high cost of the electric vehicles compared to ICE vehicles [8], [9].
2) The low profitability margin imposed on automakers by the high production cost associated with current EV technology (because of low demand) [10]. In addition to high weight and size, the estimated cost of a Li-ion battery is about US $\$ 700 / \mathrm{kWh}$, which makes the price of an EV almost double that of its fossil fuel counterpart, with nearly half of the total cost being taken up by the battery [11].

To overcome these disadvantages, a wireless power transfer (WPT) system is developed for charging EV when it's in parking times (just park your car and leave), or on-road (drive and charge). WPT system for charging EV is more convenient whereby no need a physical connection to deal with heavy, dirty, and possibly frozen cables. Also, the WPT system is precisely safe even in rainy conditions and can be compatible with different car's types. Using On-road charging EV is possible to be driven forever, as well as reduce the battery capacity to $20 \%$ [12].

MIT research team in 2007 proved that using a strongly coupled magnetic resonance WPT system can efficiently transfer power for long 
distance [13]. Rely on that published results, the WPT system becomes very attractive research field, as the power electronics circuits and control [14]-[16], magnetic pad structure [17], compensation topologies [18]-[20], WPT standards and guidelines [21]-[24], and electromagnetic field shielding techniques [25]-[28].

For magnetic pad structure the coil shape, magnetic core materials and configuration, and shielding materials and shielding form are the main research points [29], [30]. Generally, in simple WPT system the transmitting coil (Tx) normally separated from the receiving coil $(\mathrm{Rx})$ by a relatively large air-gap. So the time-varying Electromagnetic Field (EMF) generated by the Tx coil must be coupled with the Rx coil through that large air-gap. Increasing air-gap or the two coils are laterally misalignment the system efficiency will be decreased. Therefore, the coupling coefficient (k) needs to be improved to enhance the system performance as well as reduce the leakage flux [31], [32]. Since many researches are asserted that the WPT system using simulations and experiments and results are in good alignments [33]-[35]. Therefore, in this paper the simulation results are used with no need to validate.

In this paper, the pad structures using different coil shapes are intensively investigated. Coupling coefficient, electromagnetic flux density, and misalignment tolerance using Finite Element Method (FEM) software (ANSYS Maxwell 16). Simulation results are depicted and compared. One-turn coreless coils for circular planar and square planar coils are analyzed. Analyzing is conducted by considering the two coil types have the same wire length $(127.23 \mathrm{~cm}), 85 \mathrm{kHz}, 20 \mathrm{~cm}$ air-gap, and the cross-sectional wire area is 0.25 $\mathrm{cm}^{2}$, to reduce the proximity effect and skin effect, Litz wire is used.

Supposing symmetrical design for the primary and the secondary sides for both types, and primary currents and phases are the same for the secondary coils for both types also.

Results show that the coupling coefficient $\mathrm{k}$ for the coreless circular coils is greater than the square one. Moreover, the electromagnetic flux density generated by circular coils is more than that generated by the counterpart, due to the large coil surface area established by circular coils for the same wire length.

\section{WPT SYSTEM FOR CHARGING EVS}

For charging EVs wirelessly, the WPT system structure consists of many stages as shown in Fig. 1. Transmitting side composed of AC utility used as the system power supply, $\mathrm{AC} / \mathrm{DC}$ converter to rectify the $\mathrm{AC}$ power, $\mathrm{DC}$ to the high-frequency converter to feeds the compensation circuit and Tx coil. Compensation circuit confirming the system work at the resonance situation.

Receiving side consists of receiver side coil, AC/DC converter, sometime using DC/DC converter to efficiently regulate the $\mathrm{DC}$ voltage received to the batteries. The AC high-frequency current at $\mathrm{Tx}$ coil produces an alternating magnetic field which in turn generates an induced current in the Rx coil, then a rectifier is used to convert the AC induced current to DC to charge the battery [36].

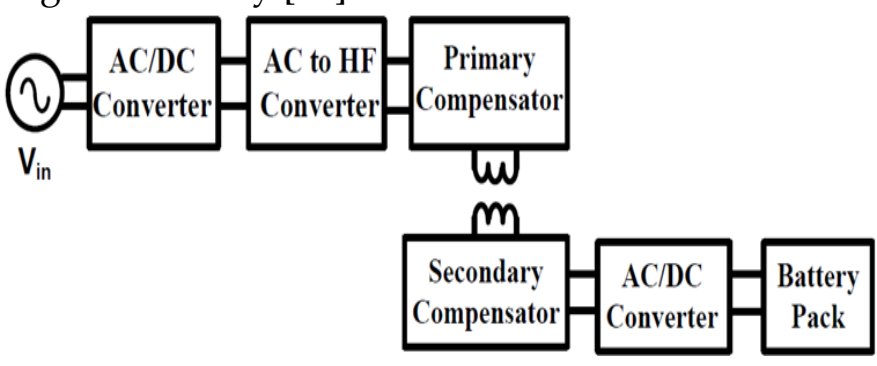

Fig.1. Structure of the inductive power transfer system for electric vehicle (EV) charging.

Fig.2 shows the equivalent circuit for the WPT system using lumped parameters model when the compensation circuit is connected in series on the primary side and series on the secondary side (series-series).

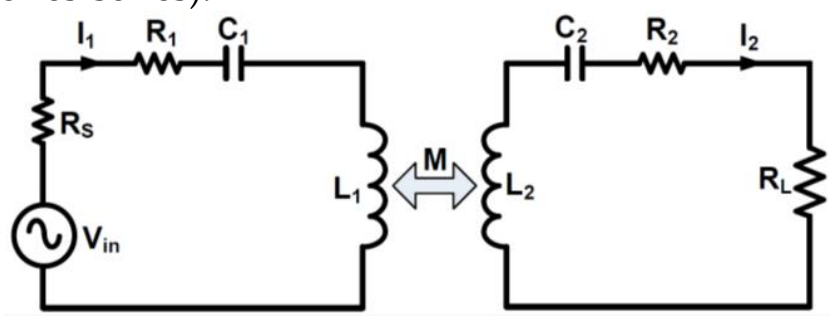

Fig.2. Wireless power transfer (WPT) equivalent circuit using a lumped parameter model.

As shown in this figure $I_{1}, C_{1}, R_{1}$ and $L_{1}$ are the primary coil current, capacitor, resistance, and inductance, respectively. Where $I_{2}, C_{2}, R_{2}$ and $L_{2}$ are the corresponding parameters for the 
secondary coil. $M$ is the mutual inductance between the two coils, and $V_{i n}, R_{s}$, and $R_{L}$ are the HF power supply, the internal resistance of the power supply, and the load resistance, respectively.

Adjusting the primary capacitor to resonate with the secondary one will significantly improve the power transferred to the load and the system performance. Therefore, using Kirchhoff's voltage law equation (1) can be obtained as:

$$
\left|\begin{array}{cc}
Z_{1}+R_{s} & j \omega M \\
j \omega M & Z_{2}+R_{L}
\end{array}\right|\left|\begin{array}{c}
I_{1} \\
I_{2}
\end{array}\right|=\left|\begin{array}{c}
V_{i n} \\
0
\end{array}\right|
$$

where

$$
\begin{aligned}
& Z_{1}=R_{1}+j \omega L_{1}+\frac{1}{j \omega C_{1}} \\
& Z_{2}=R_{2}+j \omega L_{2}+\frac{1}{j \omega C_{2}}
\end{aligned}
$$

where $\omega$ is angular frequency.

The mutual inductance $M$ can expressed in terms of coupling coefficient $k$ and the two coils inductances as follows:

$$
M=k \sqrt{L_{1} L_{2}}
$$

The power received to the load can be calculated using the uncompensated power $S_{u}(\mathrm{VA})$ and the secondary side quality factor as:

$$
P_{\text {out }}=S_{u} Q_{2}
$$

However, $S_{u}$ can be analyzed using the short circuit current $I_{s c}$ which can be calculated using the following equation:

$$
I_{s c}=\frac{M I_{1}}{L_{2}}
$$

Also the open circuit voltage $V_{o c}$ can be calculated using this equation :

$$
V_{o c}=j \omega M I_{1}
$$

The output power can be rewritten as follows:

$$
P_{\text {out }}=V_{o c} I_{s c} Q_{2}=j \omega \frac{M^{2}}{L_{2}} I_{1}^{2} Q_{2}
$$

Since the compensation capacitors on the primary and the secondary sides are tuned to ensure the system is resonate at the operating frequency, accordingly, only the real power must be consumed at the load so (7) can be written as in (8):

$$
P_{\text {out }}=\omega M I_{1} \frac{M}{L_{2}} I_{1} \cdot Q_{2}
$$

To increase $P_{\text {out }}$, angular frequency needs to be increased which is limited by improving the power electronic devices, or increase the primary current $I_{1}$ which will increase the mass of copper used for the coil and thus will increase the cost and the charger weight. Or increase $Q_{2}$ which is not more than 10 according to [37], thereby, the part $\frac{M}{L_{2}}$ is greatly dominated in boosting the power received to the load and the system performance. Therefore, it necessitates to increase it through the coil shape design and the other pad parameters structure.

Also $P_{\text {out }}$ can be expressed by the magnitude of the load current and the load resistance as in equation (7) below:

$$
\begin{aligned}
& P_{\text {out }}=\left|I_{2}\right|^{2} R_{L} \\
& =\frac{(\omega M)^{2} V_{\text {in }}}{\left\{\left(R_{s}+R_{1}\right)\left(R_{2}+R_{L}\right)+(\omega M)^{2}\right\}^{2}}
\end{aligned}
$$

The system performance $\eta$ is measured by the ratio of power transferred to the load $P_{\text {out }}$ and power input $P_{\text {in }}$ as:

$$
\begin{aligned}
& \eta=\frac{P_{\text {out }}}{P_{\text {in }}} \\
& =\frac{R_{L}}{R_{L}+R_{1}\left[\left(R_{2}+R_{L}\right) /(\omega M)\right]^{2}}
\end{aligned}
$$

where:

$$
P_{i n}=\frac{\left(R_{L}+R_{2}\right) V_{i n}^{2}}{\left(R_{s}+R_{1}\right)\left(R_{L}+R_{2}\right)+(\omega M)^{2}}
$$

\section{COILS DESIGN ANALYSIS}

One-turn coreless coils for circular and square planar coils are analyzed using FEM software. The analysis is conducted by considering the two coil types have the same wire length $(127.23 \mathrm{~cm})$, $85 \mathrm{kHz}, 20 \mathrm{~cm}$ air-gap, and the wire cross-section 
is $0.25 \mathrm{~cm}^{2}$. Supposing the equal currents and phases in both primary and secondary coils, and the design is symmetrical for primary and secondary sides for both coil types.

Fig. 3 and Fig.4 are depicted the schematic diagram of the fully aligned circular and square planar coils respectively. The structure parameters for the primary and the secondary coils for the proposed coil structures are summarized in table.1.

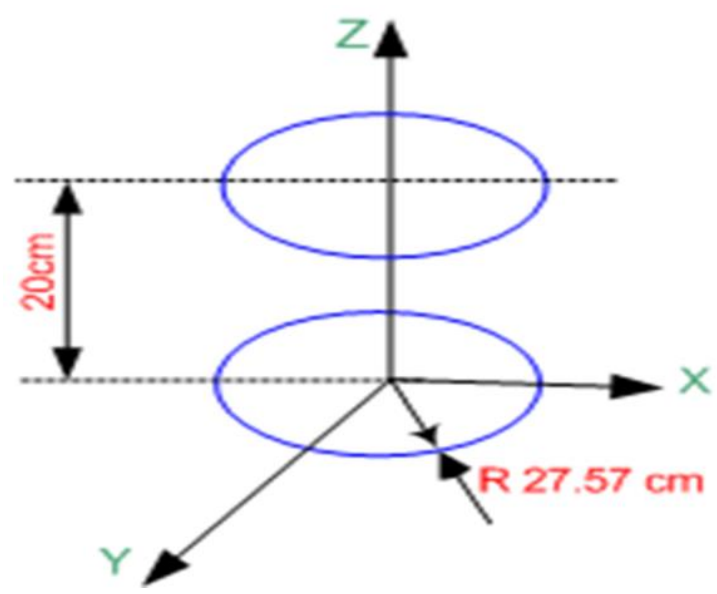

Fig.3 the conceptual schematic diagram of fully aligned circular planar coils.

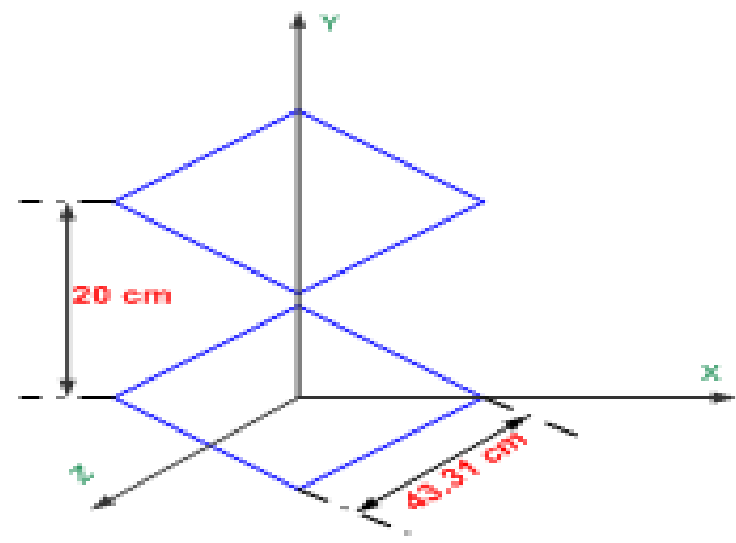

Fig.4 the conceptual schematic diagram of fully aligned square planar coils.

Table.1 structure parameters

\begin{tabular}{|c|c|}
\hline Parameter & Value \\
\hline Air gap, $\mathrm{d}$ & $20 \mathrm{~cm}$ \\
\hline Operating frequency, $\mathrm{f}$ & $85 \mathrm{kHz}$ \\
\hline Litz wire cross-section area & $0.25 \mathrm{~cm} 2$ \\
\hline Number of turns & 1 \\
\hline Litz wire length & $173.23 \mathrm{~cm}$ \\
\hline Primary coil current & $1 \mathrm{~A}$ \\
\hline Secondary coil current & $1 \mathrm{~A}$ \\
\hline
\end{tabular}

4. Simulation results and discussion.

One of the most critical parameters in designing the WPT system is transfer distance (air-gap between the primary and the secondary coils). For the much longer air-gap the coupling coefficient $(k)$ would become very small, therefore, for the desired design $k$ must be precisely evaluated.

During the practically using wireless charger, there might be lateral misalignment. Thus, will generally degraded the coupling coefficient. Therefore, the less sensitive to the misalignment design is highly required.

The coupling coefficient $k$ vs. air gap (d) curves for the two coil types are compared as depicted in Fig.5 for the range from $10 \mathrm{~cm}$ to $30 \mathrm{~cm}$. Moreover, the misalignment test for the two types is plotted in Fig.6 for the offset changes along the $X$-axis from $0 \mathrm{~cm}$ to $20 \mathrm{~cm}$. From Fig. 5 and Fig. 6 the coupling coefficient and alignment tolerance are higher for a circular coil compared to its square counterpart.

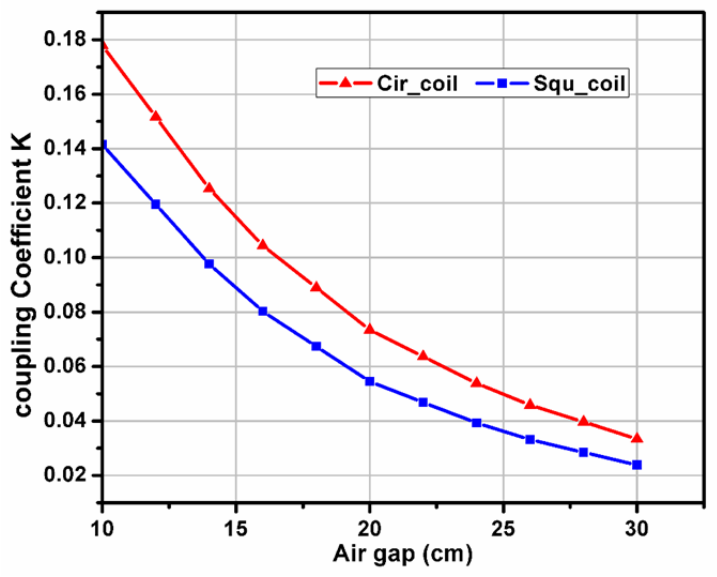

Fig.5. the coupling coefficient $k$ vs. air gap for the circular coil and square coil.

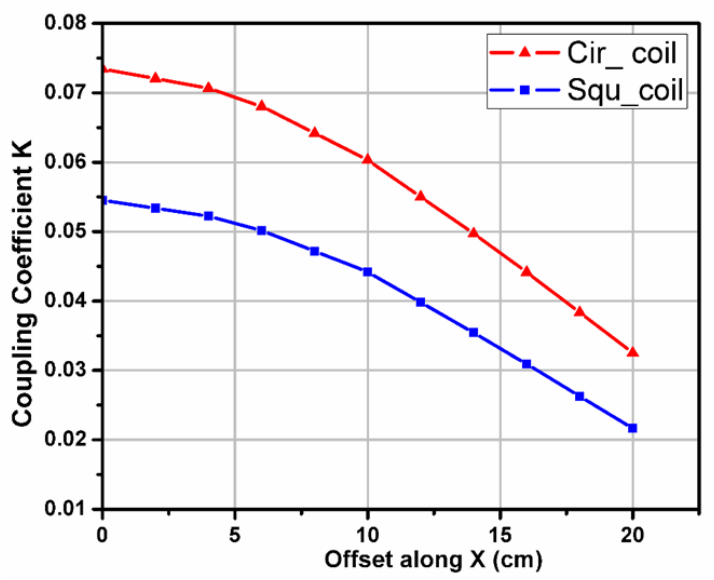

Fig.6. the coupling coefficient $k$ vs. alignment offset for the circular coil and square coil.

The amount of the time-varying electromagnetic flux (EMF) generated by the primary coil linked to the secondary coil through the air-gap will determine the system performance. So the system must be designed to ensure that the largest amount of generated EMF reaches the secondary side. 
Using Ansys Maxwell solver EMF distribution is evaluated on the $X Y$ plan $(100 \times 125 \mathrm{~cm})$ as depicted in Fig.7 and Fig.8 which presented the magnetic flux density (B) distribution inside the air-gap and surrounding the charger for the circular coil and square coil, respectively. From Fig.7 and Fig.8 it's evident that the circular coil design generates more EMF than square one; that due to the large coil surface area compared to the square coil surface area for the same wire length.

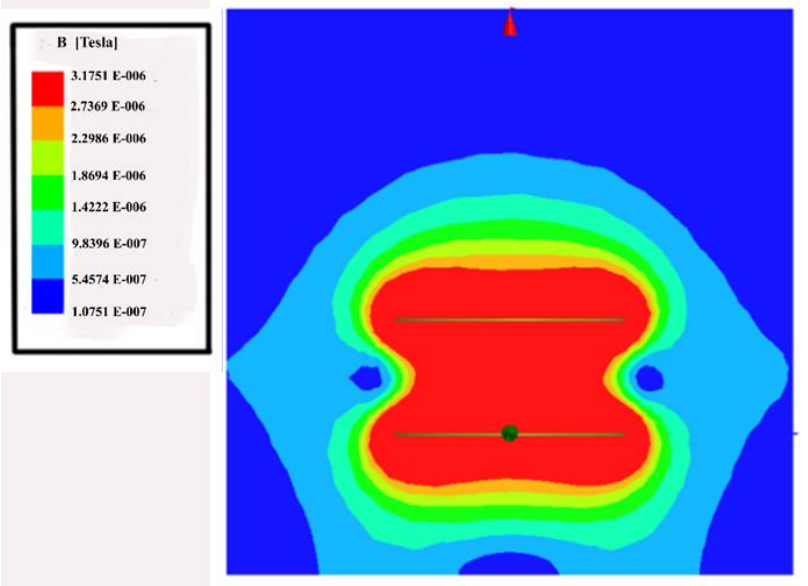

Fig.7. magnetic flux density distribution for the circular coil.

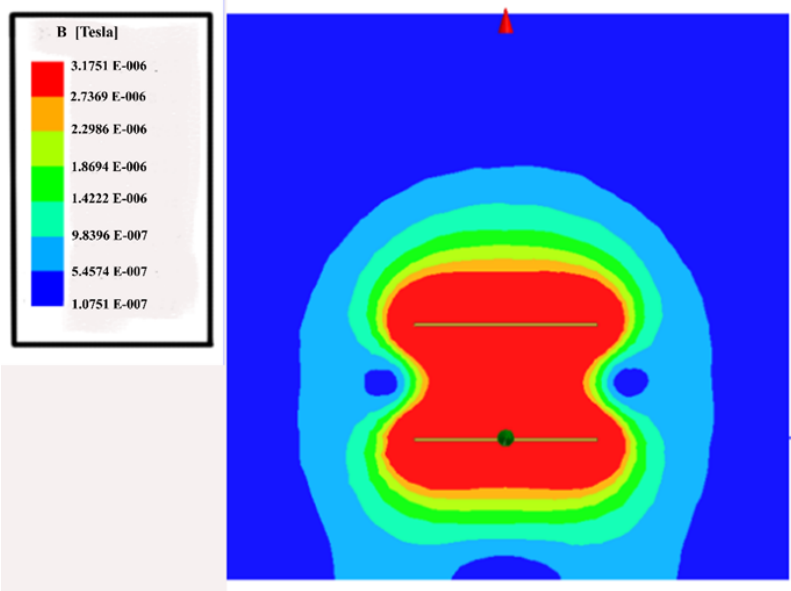

Fig.8. magnetic flux density distribution for the square coil.

\section{CONCLUSION:}

This paper presents designing WPT system for charging EVs applications. The system model is briefly discussed for the series-series compensation topology. Coils geometry is widely investigated and compared based on system performance and power transferred to the load. The circular coil geometry is simulated using FEM (Ansys Maxwell 16), and the results are compared to the square coil geometry depend on the coupling coefficients for the two types.
Results show that the circular coil geometry has a higher coupling coefficient and generates more magnetic flux inside the air-gap and surrounding the charger compared to the square one.

\section{REFERENCES}

[1]S. Chu and A. Majumdar, "Opportunities and challenges for a sustainable energy future," Nature, vol.488, pp.294-303, August 2012. [2]Environmental Protection Agency (EPA).September, 2021). Fast facts on transportation greenhouse gas emissions. Available: https://www.epa.gov/greenvehicles/fast-facts-transportation-greenh ouse-gas-emissions.

[3]P. U. Chukwu, A. Isa, J. Ojosu, and J. Olayande, "Energy consumption in transport sector in Nigeria: Current situation and ways forward," Energy, vol. 5, pp. 75-83, 2015.

[4] A. L. Paladugula, N. Kholod, V. Chaturvedi, P. P. Ghosh, S. Pal, L. Clarke, et al., "A multi-model assessment of energy and emissions for India's transportation sector through 2050," Energy Policy, vol. 116, pp. 10-18, May 2018.

[5]K. A. Kalwar, M. Aamir, and S. Mekhilef, "Inductively coupled power transfer (ICPT) for electric vehicle charging - A review," Renewable \& Sustainable Energy Reviews, vol. 47, pp. 462-475, July 2015.

[6]A. Gil and J. Taiber, "A literature review in dynamic wireless power transfer for electric vehicles: Technology and infrastructure integration challenges," Sustainable automotive technologies, pp. 289-298, 2014.

[7]Ł. Sobol and A. Dyjakon, "The influence of power sources for charging the batteries of electric cars on $\mathrm{CO} 2$ emissions during daily driving: a case study from Poland," Energies, vol. 13, pp. 1-18, January 2020.

[8]D. M. Vilathgamuwa and J. P. K. Sampath, "Wireless Power Transfer (WPT) for Electric Vehicles (EVs) - Present and Future Trends," In Plug in electric vehicles in smart grids, Singapore: Springer, 2015 ch2, pp. 33-60.

[9]C. Duan, C. Jiang, A. Taylor, and K. Bai, "Design of a zero-voltage-switching large-air-gap wireless charger with low electric stress for electric vehicles," Iet Power Electronics, vol. 6, pp. 1742-1750, November 2013.

[10] J. Huh, W. Lee, G. H. Cho, and B. Lee, "Characterization of novel Inductive Power Transfer Systems for On-Line Electric Vehicles," in Applied Power Electronics Conference and Exposition, 2011, pp. 1975-1979.

[11] H. H. Wu, A. Gilchrist, K. Sealy, P. Israelsen, and J. Muhs, "A review on inductive charging for electric vehicles," in Electric Machines \& Drives Conference, 2011, pp. 143-147.

[12] F. Musavi, M. Edington, and W. Eberle, "Wireless power transfer: A survey of EV battery charging technologies," in 2012 IEEE Energy Conversion Congress and Exposition (ECCE), 2012, pp. 1804-1810.

[13] A. Kurs, "Power transfer through strongly coupled resonances," Ph.D. dissertation, Massachusetts Institute of Technology, Cambridge, MA, 2007.

[14] L. Yang, Y. Shi, M. Wang, and L. Ren, "Constant Voltage Charging and Maximum Efficiency Tracking for WPT Systems Employing Dual-Side Control Scheme," IEEE Journal of Emerging and Selected Topics in Power Electronics, August 2021.

[15] Y. Li, S. Liu, X. Zhu, J. Hu, M. Zhang, R. Mai, et al., "Extension of ZVS region of series-series WPT systems by an auxiliary variable inductor for improving efficiency," IEEE Transactions on Power Electronics, vol. 36, pp. 7513-7525, December 2020.

[16] B. M. Mosammam, N. Rasekh, M. Mirsalim, and A. Khorsandi, "Electromagnetic analysis for dd pad magnetic structure of a wireless power transfer (WPT) for electrical vehicles," in 2018 Smart Grid Conference (SGC), 2018, pp. 1-6. 
[17] G. Rituraj and P. Kumar, "A New Magnetic Structure of Unipolar Rectangular Coils in WPT Systems to Minimize the Ferrite Volume While Maintaining Maximum Coupling," IEEE Transactions on Circuits and Systems II: Express Briefs, vol. 68, pp. 2072-2076, September 2020.

[18] N. Rasekh, N. Rasekh, and M. Mirsalim, "Evaluation Study of Different Integration Methods of LCC Compensation Network for Various Types of Magnetic Structures of Wireless Power Transfer," in 2021 29th Iranian Conference on Electrical Engineering (ICEE), 2021, pp. 284-289.

[19] Z. Liu, L. Wang, Y. Guo, and S. Li, "Primary-Side Linear Control for Constant Current/Voltage Charging of the Wireless Power Transfer System Based on the LCC-N Compensation Topology," IEEE Transactions on Industrial Electronics, September 2021.

[20] T. Campi, S. Cruciani, F. Maradei, and M. Feliziani, "Magnetic Field during Wireless Charging in an Electric Vehicle According to Standard SAE J2954," Energies, vol. 12, pp. 1-24, January 2019. [21] D. Bululukova and M. Kramer, "Application of existing wireless power transfer standards in automotive applications," in 2014 International Conference on Connected Vehicles and Expo (ICCVE), pp. 863-864, November 2014.

[22] H. W. Ott and H. W. Ott, Noise reduction techniques in electronic systems, vol. 442: Wiley New York, 1988.

[23] N. Listed, "Guidelines for limiting exposure to time-varying electric, magnetic, and electromagnetic fields (up to $300 \mathrm{GHz}$ ). International Commission on Non-Ionizing Radiation Protection," Health Physics, vol. 74, pp. 494-522, 1998.

[24] I. C. o. N.-I. R. Protection, "Guidelines for limiting exposure to time-varying electric and magnetic fields ( $1 \mathrm{~Hz}$ to $100 \mathrm{kHz})$," Health physics, vol. 99, pp. 818-836, December 2010.

[25] K. E. I. Elnail, X. Huang, and L. Tan, "Optimal resonance reactive current shielding design in wireless power transfer systems," in 2017 China International Electrical and Energy Conference (CIEEC), pp. 750-753, China 2017.

[26] K. E. I. Elnail, L. Huang, L. Tan, S. Wang, and X. Wu, "Resonant reactive current shield design in WPT systems for charging EVs," in 2018 IEEE PES Asia-Pacific Power and Energy Engineering Conference (APPEEC), pp. 56-59, Malaysia 2018,

[27] L. Tan, K. E. I. Elnail, M. Ju, and X. Huang, "Comparative analysis and design of the shielding techniques in WPT systems for charging EVs," Energies, vol. 12, pp. 1-20, June 2019.
[28] K. E. I. Elnail, X. Huang, C. Xiao, L. Tan, and X. Haozhe, "Core structure and electromagnetic field evaluation in wpt systems for charging electric vehicles," Energies, vol. 11, pp. 1734, July 2018. [29] A. A. Mohamed, A. A. Shaier, H. Metwally, and S. I. Selem, "A comprehensive overview of inductive pad in electric vehicles stationary charging," Applied Energy, vol. 262, pp. 114584, March 2020.

[30] D.-W. Seo, J.-H. Lee, and H.-S. Lee, "Optimal coupling to achieve maximum output power in a WPT system," IEEE Transactions on Power Electronics, vol. 31, pp. 3994-3998, December 2015.

[31] G. Rituraj, B. K. Kushwaha, and P. Kumar, "A unipolar coil arrangement method for improving the coupling coefficient without ferrite material in wireless power transfer systems," IEEE

Transactions on Transportation Electrification, vol. 6, pp. 497-509, May 2020.

[32] S. Li and C. C. Mi, "Wireless power transfer for electric vehicle applications," IEEE journal of emerging and selected topics in power electronics, vol. 3, pp. 4-17, April 2014.

[33] R. Bosshard, J. W. Kolar, and B. Wunsch, "Accurate finite-element modeling and experimental verification of inductive power transfer coil design," in 2014 IEEE Applied Power Electronics Conference and Exposition-APEC 2014 , pp. 1648-1653, March 2014. [34] L. Chen, S. Liu, Y. C. Zhou, and T. J. Cui, "An optimizable circuit structure for high-efficiency wireless power transfer," IEEE

Transactions on Industrial Electronics, vol. 60, pp. 339-349, December 2011.

[35] G. Kim and B. Lee, "Analysis of magnetically coupled wireless power transfer between two resonators based on power conservation," in 2014 IEEE Wireless Power Transfer Conference, pp. 231-234, May 2014.

[36] H. Xu, C. Wang, D. Xia, and Y. Liu, "Design of magnetic coupler for wireless power transfer," Energies, vol. 12, pp. 3000, January 2019.

[37] A. W. Green and J. Boys, "10 kHz inductively coupled power transfer-concept and control," Proceedings of 5th International Conference on Power Electronics and Variable-Speed Drives, pp. $694-$ 699, London, UK, October 1994. 